\title{
Correlates of plasma homocysteine, cysteine and cysteinyl-glycine in respondents in the British National Diet and Nutrition Survey of Young People Aged 4-18 Years, and a comparison with the Survey of People Aged 65 Years and Over
}

\author{
C. J. Bates ${ }^{1 *}$, M. A. Mansoor ${ }^{2}$, Jan Gregory ${ }^{3}$, Kristina Pentieva ${ }^{4}$ and Ann Prentice ${ }^{1}$ \\ ${ }^{1}$ MRC Human Nutrition Research, Elsie Widdowson Laboratory, Fulbourn Road, Cambridge CB1 9NL, UK \\ ${ }^{2}$ Department of Clinical Chemistry, Central Hospital in Rogaland, Stavanger, Norway \\ ${ }^{3}$ Office for National Statistics, Social Survey Division, 1 Drummond Gate, London SWIV 2QQ, UK \\ ${ }^{4}$ Northern Ireland Centre for Diet and Health, School of Biomedical Sciences, University of Ulster, Coleraine, Co. \\ Londonderry, Northern Ireland BT52 1SA, UK
}

(Received 1 February 2001 - Revised 2 August 2001 - Accepted 6 September 2001)

\begin{abstract}
Plasma total homocysteine (tHcy), cysteine and cysteinyl-glycine were measured in a representative sample of 922 young people aged 4-18 years, participating in the National Diet and Nutrition Survey in mainland Britain in 1997. Both tHcy and cysteine increased markedly with age; cysteinyl-glycine less so. Neither tHcy nor cysteine differed between genders; cysteinyl-glycine was higher in males. tHcy concentrations were lowest in the winter; cysteine and cysteinyl-glycine varied only slightly with season. In respondents aged $>15$ years, tHcy was higher in smokers, but in respondents aged 7-11 years, tHcy was higher in those whose mothers smoked. tHcy was inversely correlated with serum folate, serum vitamin $\mathrm{B}_{12}$ and vitamin $\mathrm{B}_{6}$ status, but neither cysteine nor cysteinyl-glycine shared these relationships. The relationships between tHcy and B-vitamin status indices ran parallel with those of the 65 years and over survey, but at much lower tHcy concentrations for any given B-vitamin concentration. Age-adjusted tHcy was not correlated with anthropometric indices, blood pressure, haematology, plasma creatinine, urea or cholesterol, but was directly correlated with fasting triacylglycerol. We conclude that disease-risk indices, like tHcy and perhaps cysteine, if established during early life, may be modulated by diet and lifestyle, thereby providing an opportunity for public health intervention.
\end{abstract}

Homocysteine: National Diet and Nutrition Survey: Vitamins: Children

Plasma total homocysteine (tHcy) is well established as a powerful risk indicator and probable risk determinant for a wide range of vascular diseases in all age groups of Western society (Ueland et al. 1992; Alfthan et al. 1994; Arnesen et al. 1995; Boushey, 1995; Danesh \& Lewington, 1998; Refsum et al. 1998; Nygard et al. 1999; Selhub, 1999). A number of dietary and status index correlates or determinants of tHcy have been identified, the most powerful and robust of which include the B-vitamins: folate, vitamin $\mathrm{B}_{12}$ and vitamin $\mathrm{B}_{6}$, whose metabolic functions are intimately connected with the metabolic pathways of homocysteine disposition (Brattstrom et al. 1988; Rosenberg, 1996; Verhoef et al. 1996; HomocysteineLowering-Triallists'-Collaboration, 1998; Malinow et al. 1998; Omenn et al. 1998; Pietrzik \& Bronstrup 1998;
Robinson et al. 1998; Selhub, 1999). Research has so far focussed mainly on the determinants of tHcy in later life, and there is a paucity of information about the determinants of tHcy in representative samples of healthy children and young people, especially in Britain.

Homocysteine, cysteine and cysteinyl-glycine are all metabolically inter-related (Mansoor et al. 1992), and these thiol species in plasma are probably important in determining the redox milieu and free radical generation rates (Mansoor et al. 1992, 2000; Ueland et al. 1996; Enoiu et al. 2000). A correlation between plasma cysteine and vascular disease risk, independent of its correlation with tHcy, has recently been described (Mansoor et al. 1995; ElKhairy et al. 1999, 2001). Therefore, the measurement of plasma cysteine and cysteinyl-glycine (which can be

\footnotetext{
Abbreviations: NDNS, National Diet and Nutrition Survey; tHcy, total homocysteine.

* Corresponding author: Dr Chris Bates, fax +44 1223 437515, email Chris.Bates@mrc-hnr.cam.ac.uk
} 
performed in the same chromatography run as tHcy) is of potential interest for the understanding of biological interrelationships and for disease prediction. The possibility of risk-related geographical variations in tHcy (Bates et al. 1997), of smoking-related variations (Refsum et al. 1998), and of seasonal variations in cardiovascular risk factors (Woodhouse et al. 1994) provided the rationale for also examining these potential socio-demographic determinants.

The National Diet and Nutrition Survey (NDNS): Young People Aged 4-18 Years was commissioned jointly by the Department of Health and the Ministry of Agriculture, Fisheries and Food in mainland Britain, and carried out during 1997 (Gregory et al. 2000). Responsibility for this survey and the NDNS Programme transferred from the Ministry of Agriculture, Fisheries and Food to the Food Standards Agency on its establishment in April 2000. The present publication describes the population distribution of tHcy, cysteine and cysteinyl-glycine, and thus provides reference values for the British population for this age range. It also compares them with values observed in British people aged 65 years and over, from a previous NDNS (Bates et al. 1997; Finch et al. 1998), which used similar survey procedures and assay methodologies, and can thus provide a robust comparison between representative samples of contrasting age groups of the British population.

\section{Respondents and methods}

The design and execution of the NDNS of Young People Aged 4-18 Years has been described (Gregory et al. 2000); therefore only the main features are summarised here. The Social Survey Division of the Office for National Statistics recruited young people from 132 postcode sectors, randomly selected from mainland Britain, in four waves corresponding to the four seasons, during 1997. Within each sector, a sample of addresses was selected and was approached by post to establish the number of private households at each address and the age and gender of each of the residents in these households. From the responses, a further random selection then achieved the required numbers of each sex, for the four age groups: 4-6 years, 7-10 years, $11-14$ years and $15-18$ years (one respondent in the latter age group had just passed his nineteenth birthday when his blood sample was taken, but the data are nevertheless included in the 15-18-year age group).

Of 2672 young people who were eligible to participate, $2127(80 \%)$ cooperated by completing an interview with a trained interviewer in their own home. Current smoking habit (yes/no) was ascertained by questionnaire, from both the young person (respondent) and their parent(s) respectively, but biochemical confirmation was not used. Of the respondents, 1701 completed a consecutive $7 \mathrm{~d}$ weighed dietary record of all food and drink consumed, and 1193 provided a blood sample which, in most cases, was an early morning, fasting sample.

As noted in the survey report (Gregory et al. 2000) the survey refusals (non-respondents) were more commonly in the 15-18-year age group than were the partial or full respondents, and of those who did cooperate, a smaller proportion in the 4-6-year group than in the other groups provided a blood sample. There was also some variation in cooperation between waves and between regions, particularly in the proportion of respondents who provided a blood sample. However, a detailed comparison between those respondents who provided a blood sample that was subsequently used for the analysis of the thiol species and those who did not (either because they provided no blood sample, or because there was insufficient for this particular analysis, or because permission for it was not given) showed no evidence of differences in socio-economic indices, in nutrient intakes or in other blood status indices, including those of the key B vitamins. Therefore we consider that there is unlikely to have been any selection bias which could have caused significant confounding of the conclusions of the present study.

Blood was taken by a trained phlebotomist in the respondents' own homes. Two sub-samples were sent by first class post to Great Ormond Street Hospital Haematology Laboratory for routine haematology measurements and for analyses of serum and whole-blood folate and serum vitamin $B_{12}$. A sample of heparinised blood was immediately chilled in a cold-box, and was taken by the phlebotomist to a local hospital laboratory within 0.5 to $2 \mathrm{~h}$, where it was immediately separated to yield plasma and saline-washed erythrocytes. These samples were stored frozen for up to 3 months at $-40^{\circ} \mathrm{C}$ or lower, and then at $-85^{\circ} \mathrm{C}$ until analysed. Except for the thiol species, most of the biochemical status analyses were performed at Medical Research Council Human Nutrition Research in Cambridge, within 2 years of collection.

The measurements of serum and whole-blood folate and serum vitamin $\mathrm{B}_{12}$ were performed by Abbott IMx analyses at Great Ormond Street Haematology Laboratory (Fiore et al. 1988; Kuemmerle et al. 1992; Wilson et al. 1995). The measurements of vitamin $\mathrm{B}_{6}$ (pyridoxal phosphate and its breakdown product, pyridoxic acid) were performed by HPLC after oxidation with alkaline cyanide (Bates et al. 1999a). The tHcy, cysteine and cysteinyl-glycine analyses were carried out on heparinised plasma samples within 3 years of sample collection, by an HPLC-based method (Fiskerstrand et al. 1993), in the Department of Clinical Chemistry, Central Hospital in Rogaland, Stavanger, Norway. It was confirmed that the inter-assay $\mathrm{CV}$ for the tHcy, cysteine and cysteinyl-glycine assay in control samples was less than $10 \%$ in all cases (see Fiskerstrand et al. 1993). The assay procedure has been shown to yield results that agree closely with those of the procedure (Mansoor et al. 1992) that was used previously in the same laboratory for the assay of samples from the survey of people aged 65 years and over (Bates et al. 1997) and also with the results from other laboratories participating in an international external quality assurance scheme (Moller et al. 1999). It has also been demonstrated that plasma tHcy remains stable even at $-20^{\circ} \mathrm{C}$, for at least 6 years (Israelsson et al. 1993). Therefore, no significant degradation was likely during 3 years storage a $-80^{\circ} \mathrm{C}$. The other relevant survey assays are described in the survey report (Gregory et al. 2000). The vitamin $B_{6}$ status values obtained for the NDNS 4-18-year and the NDNS 65 years and over surveys are described elsewhere (Bates et al. 1999b). 
The data from the survey of people aged 65 years and over were confined to those living in the community ('freeliving sample') (Finch et al. 1998).

Permission for the survey procedures was obtained from the Local Research Ethics Committees associated with each postcode sector. Separate permission from each of the Local Research Ethics Committees was obtained for the analysis of tHcy, cysteine and cysteinyl-glycine, and analysis was limited to those respondents who gave their written permission for the further analysis of stored plasma residues.

\section{Statistical methods}

Statistical analyses were performed by DataDesk (Data Description Inc.) statistical package. The plasma tHcy dataset was positively skewed (skewness coefficient 5.1), therefore all calculations involving tHcy used $\log _{\mathrm{e}^{-}}$ transformed values, followed by back-transformation where appropriate. Although not strictly necessary in terms of skewness, for consistency the calculations involving plasma cysteine and cysteinyl-glycine in Tables 1 and 2 also used $\log _{\mathrm{e}}$-transformed values followed by backtransformation. In Tables 2, 4 and 5, the potential determinants of tHcy, cysteine and cysteinyl-glycine were entered as either continuous (for age only) or discrete-value variables in a general linear (one-way ANOVA after grouping where necessary) multivariate model, which reported mean-adjusted values and the overall significance of the contribution of each variable to the ANOVA model. In Table 3, a range of biochemical covariates (continuous variables) was entered, together with age and season, in a multivariate regression model, followed by backwards elimination until only those which remained significant contributors, at $P<0.05$, remained. For Fig. 1, the B-vitamin index determinants were categorised into ascending tenths of their distribution, the geometric mean values of tHcy and of the B-vitamin index were then calculated for each tenth, and these were plotted. For all significance calculations, $P<0.05$ was accepted as significant.

\section{Results}

Table 1 presents the geometric mean and inner $95 \%$ ranges by age group for the three thiol species: tHcy, cysteine, and cysteinyl-glycine, in plasma. Both tHcy and cysteine exhibited progressive increases with age throughout the age range, and these were highly significant for both genders $(P<0.0001)$. Cysteinyl-glycine, however, did not share this strong relationship with age; moreover it was the only one of the three species to exhibit a major gender difference, which was, in turn, largely confined to the oldest (15 years and over) age group. Of the other species, tHcy exhibited a marginally significant gender difference, with slightly higher values in males in the oldest age group.

Although the population sample had been randomly selected, it did not exactly match the entire (census) population. In order to test whether this minimal deviation had any measurable effect on the results, a 'weighting variable', designed to represent the ratio of numbers in each population category of the survey sample to those in the entire census population (Gregory et al. 2000), was applied. This was achieved by using the reciprocal of the weighting variable as the 'variance variable' in the DataDesk general linear model. However, this adjustment was found to make less than $1 \%$ difference to $85 \%$ of the calculations in Table 1 , and in no case did the adjusted value differ by more than $3 \%$ from the corresponding unadjusted value. Therefore, it was concluded that the weighting adjustment could be dispensed with, for the purposes of the present study.

Table 1. Distribution of geometric means (GM) for total homocysteine (tHcy), cysteine and cysteinyl-glycine, by gender and age group, in four subgroups of the National Diet and Nutrition Survey 4-18-yearsold respondents*

\begin{tabular}{|c|c|c|c|c|c|c|c|}
\hline \multirow{2}{*}{$\begin{array}{l}\text { Age group } \\
\text { (years) } \dagger\end{array}$} & \multirow[b]{2}{*}{$n$} & \multicolumn{2}{|c|}{$\begin{array}{c}\text { tHcy } \\
(\mu \mathrm{mol} / \mathrm{l}) \ddagger\end{array}$} & \multicolumn{2}{|c|}{$\begin{array}{l}\text { Cysteine } \\
(\mu \mathrm{mol} / \mathrm{l}) \ddagger\end{array}$} & \multicolumn{2}{|c|}{$\begin{array}{l}\text { Cysteinyl-glycine } \\
(\mu \mathrm{mol} / \mathrm{l}) \ddagger\end{array}$} \\
\hline & & GM & $95 \%$ range & GM & $95 \%$ range & GM & $95 \%$ range \\
\hline \multicolumn{8}{|l|}{ Males } \\
\hline $4.00-6.99$ & $49-51$ & $5 \cdot 16$ & $2 \cdot 7-9.5$ & 188 & $114-238$ & $32 \cdot 3$ & $18 \cdot 8-49 \cdot 7$ \\
\hline $7 \cdot 00-10 \cdot 99$ & $125-131$ & 5.59 & $3 \cdot 1-9 \cdot 5$ & 203 & $145-264$ & $36 \cdot 1$ & $22 \cdot 8-53 \cdot 7$ \\
\hline $11.00-14.99$ & $156-157$ & $6 \cdot 18$ & $2.9-11.5$ & 214 & $161-273$ & 38.3 & $25 \cdot 0-58 \cdot 7$ \\
\hline $15 \cdot 00-18.99$ & 140 & 8.54 & $4 \cdot 1-20 \cdot 1$ & 227 & $165-286$ & 38.6 & $24 \cdot 7-55 \cdot 3$ \\
\hline \multicolumn{8}{|l|}{ Females } \\
\hline $4 \cdot 00-6.99$ & 62 & 4.79 & $2 \cdot 2-8 \cdot 1$ & 194 & $123-253$ & 34.9 & $17 \cdot 2-50 \cdot 4$ \\
\hline $7.00-10.99$ & $107-109$ & $5 \cdot 69$ & $2 \cdot 7-10 \cdot 6$ & 207 & $152-271$ & 35.8 & $24 \cdot 1-53 \cdot 1$ \\
\hline $11.00-14.99$ & $137-140$ & $6 \cdot 40$ & $3.5-11 \cdot 8$ & 216 & $160-267$ & $36 \cdot 1$ & $23 \cdot 4-55.9$ \\
\hline $15 \cdot 00-18.99$ & $140-144$ & $7 \cdot 80$ & $3 \cdot 9-14 \cdot 3$ & 232 & $164-289$ & 33.4 & $21 \cdot 3-53 \cdot 6$ \\
\hline
\end{tabular}

*For details of respondents and procedures, see p. 72

†The age groups are given to two decimal points in this table, but are rounded to integers elsewhere.

$\ddagger$ All the tabulated data were obtained by back-transformation from the means and ranges of $\log _{e}$ values, so as to normalise skewed distributions, especially for tHcy. By linear regression with adjustment for age and season, only cysteinyl-glycine exhibited a significant overall gender difference, which was confined mainly to the oldest age group, males having higher values than females $(P<0.0001)$. There was also a marginally significant $(P=0.044)$ gender difference for tHcy in the oldest age group; however cysteine exhibited no significant gender difference for any age group. The significance of the overall linear regression of each log-transformed analyte with age was: for tHcy, $P<0.0001$; for cysteine, $P<0.0001$; for cysteinyl-glycine, $P=0.045$. 
Table 2. Seasonal variation of homocysteine, cysteine and cysteinyl-glycine values in young people aged $4-18$ years and in free-living adults aged 65 years and over in Britain*

\begin{tabular}{|c|c|c|c|c|}
\hline Season & $n$ & $\begin{array}{l}\text { Homocysteine } \\
(\mu \mathrm{mol} / \mathrm{l}) \dagger\end{array}$ & $\begin{array}{l}\text { Cysteine } \\
(\mu \mathrm{mol} / \mathrm{l}) \dagger\end{array}$ & $\begin{array}{c}\text { Cysteinyl-glycine } \\
(\mu \mathrm{mol} / 1) \dagger\end{array}$ \\
\hline \multicolumn{5}{|l|}{ Young people aged $4-18$ years } \\
\hline Winter (January-March) & $185-188$ & $5 \cdot 20$ & 218 & 35.9 \\
\hline Spring (April-June) & $159-165$ & $6 \cdot 37$ & 215 & $35 \cdot 2$ \\
\hline Summer (July-September) & 294 & $7 \cdot 22$ & 207 & $32 \cdot 2$ \\
\hline Autumn (October-December) & 282 & $6 \cdot 60$ & 217 & 41.4 \\
\hline$F$ ratio for seasonal difference & & $41 \cdot 3$ & $7 \cdot 7$ & 74.5 \\
\hline$P$ & & $<0.0001$ & $<0.0001$ & $<0.0001$ \\
\hline \multicolumn{5}{|c|}{ Adults aged 65 years and over (free-living) } \\
\hline Winter (January-March) & $153-161$ & $12 \cdot 86$ & 272 & $34 \cdot 0$ \\
\hline Spring (April-June) & $163-166$ & $15 \cdot 47$ & 255 & $35 \cdot 3$ \\
\hline Summer (July-September) & 186 & $15 \cdot 06$ & 254 & $36 \cdot 2$ \\
\hline Autumn (October-December) & 238 & $15 \cdot 06$ & 261 & $35 \cdot 7$ \\
\hline$F$ ratio for seasonal difference & & $9 \cdot 39$ & 11.55 & $2 \cdot 19$ \\
\hline$P$ & & $<0.0001$ & $<0.0001$ & 0.09 \\
\hline
\end{tabular}

* For details of respondents and procedures, see p. 72.

†All values are back-transformed from means of $\log _{\mathrm{e}}$-transformed values and are adjusted for age (within the two age groups), and the values in adults aged 65 years and over are also adjusted for gender.

Table 2 reveals the existence of a significant seasonal variation in all three thiol species. As shown also in Table 2, this seasonal variation was seen not only in the young people's survey, but also in the survey of people aged 65 years and over. In both age groups, the lowest mean values of tHcy were observed in the winter months, with generally higher values during spring, summer and autumn. Although there was some evidence of seasonal variations in the key B-vitamin status indices (but not of their intakes) that could partly account for the observed variation in tHcy concentrations (not shown), this accounted for only a small proportion of the seasonal variance on plasma tHcy. In contrast to tHcy, cysteine exhibited the lowest values in the summer, and this was also true for cysteinyl-glycine in the young people, although in the 65 years and over survey there was no significant seasonal variation in cysteinylglycine. Amongst other blood status indices which are known to determine vascular disease risk in older people, total and LDL-cholesterol and diastolic blood pressure exhibited their maximum levels in the winter, and plasma vitamin $\mathrm{C}$ exhibited minimum levels in the winter, in the $4-$ 18-year survey (not shown). In contrast, HDL-cholesterol, systolic blood pressure and white cell count did not exhibit any significant seasonal variations in the 4-18-year survey (not shown).

Table 3 lists the biochemical status indices which were significantly correlated with tHcy in a multivariate model in which age, season, and forty-six blood status indices (comprising haematology indices; plasma fat-soluble vitamin status indices for vitamins $\mathrm{A}, \mathrm{D}, \mathrm{E}$ and carotenoids; water-soluble vitamin indices in serum, plasma or erythrocytes; mineral indices including bone-related minerals, $\mathrm{Fe}, \mathrm{Zn}, \mathrm{Cu}$ and Se; plasma total- and HDL-cholesterol and plasma $\alpha_{1}$-antichymotripsin (index of acute phase status)) were introduced, and were then removed by backwards elimination, until those remaining all contributed at a significance of $P<0 \cdot 05$. The significance of the five indices in the multivariate model, including triacylglycerol, was unaffected by the omission of fourteen respondents who reported not complying with the fasting conditions for the collection of the blood sample. The significance of the relationships between tHcy and these five indices (including pyridoxic acid) was very little affected by adjustment for both plasma creatinine and plasma urea (not shown), suggesting that kidney function was not a major confounding factor in this age group. The overall correlations between tHcy and folate, vitamin $B_{12}$ and vitamin $B_{6}$ intakes, adjusted for age, season and energy intake, were inverse and significant at $P<0.0001$ in all three cases (not shown).

tHcy was strongly and directly correlated with both cysteine and cysteinyl-glycine, after adjustment for age and

Table 3. Multivariate linear regression* between $\log _{e}$-transformed homocysteine and biochemical status indices in young people aged $4-18$ years $†$

\begin{tabular}{lcccc}
\hline Status index & Fratio & $\begin{array}{c}\text { Coefficient } \\
\left(\times 10^{-4}\right)\end{array}$ & $\begin{array}{c}\text { SE } \\
\left(\times 10^{-4}\right)\end{array}$ & $P$ \\
\hline Serum folate & 92.3 & -134 & 16.5 & $<0.0001$ \\
Serum vitamin $\mathrm{B}_{12}$ & 11.8 & -2.52 & 0.73 & 0.0015 \\
Plasma triacylglycerol & 8.4 & +640 & 220 & 0.006 \\
Plasma pyridoxic acid & 6.0 & -51.2 & 20.8 & 0.012 \\
Erythrocyte superoxiden dismutase & 6.7 & -1.07 & 0.41 & 0.013 \\
\hline
\end{tabular}

*All regression calculations were adjusted for age and for season. The multivariate analysis (d.f. 759) was by backwards elimination, until all remaining relationships were significant at $P<0.05$.

†For details of respondents and procedure, see p. 72. 

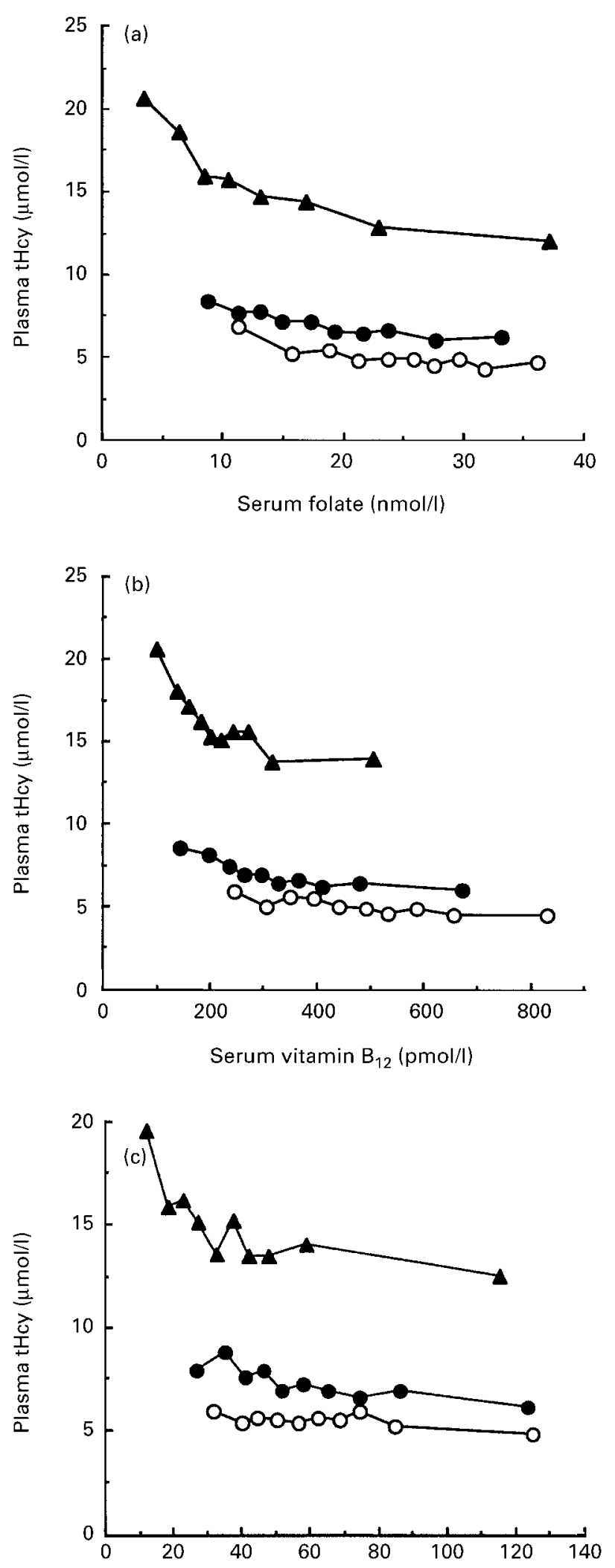

Plasma pyridoxal phosphate $(\mathrm{nmol} / \mathrm{l})$ gender (not shown). The biochemical correlates of cysteine and cysteinyl-glycine differed from those of tHcy insofar that they were both much less strongly correlated with B-vitamin status indices, especially with serum folate and vitamin $\mathrm{B}_{12}$.

Fig. 1 depicts the relationships observed between tHcy and (a), serum folate; (b), serum vitamin $\mathrm{B}_{12}$; (c), plasma pyridoxal phosphate, for two age ranges of the young people, and for the free-living survey participants aged 65 years and over. Although there is a large vertical difference between the three age groups, there is also a strong parallelism with respect to the relationships between tHcy and the B-vitamin status indices at all ages. Among the older respondents, there were many with low B-vitamin status indices, but there was also a small subgroup with high serum B-vitamin concentrations, resulting from the regular use of dietary supplements.

Table 4 explores the relationships between tHcy and smoking habit (respondent's own and maternal smoking). There was a marginally-significant difference in plasma tHcy between smokers and non-smokers in the oldest age group, and unexpectedly, a more highly significant difference in tHcy between those whose mothers smoked and those whose mothers did not, in one of the younger age groups.

Table 5 explores geographical variations in mean tHcy concentrations. Although less highly significant than in the survey of older people (Bates et al. 1997), there was evidence for higher values in the north of Britain. After adjustments for age and season, there were also significant north-south gradients for serum folate $(P=0.005)$, for serum vitamin $\mathrm{B}_{12}(P=0.05)$ and for plasma pyridoxic acid $(P=0 \cdot 05)$. All of these gradients indicated better vitamin status in the south than in the north of the country.

Possible relationships between plasma tHcy and the following socioeconomic, anthropometric and health indices were also examined: social class of head of household; household income; receipt of income supplements or credits; maternal educational qualification level; maternal age; ethnic group; whether the subject was vegetarian; consumption of tea or coffee; body weight; height; BMI; mid-upper-arm circumference; systolic and diastolic blood pressure. After adjustment for age and

Fig. 1. Plasma total homocysteine(tHcy) $v$. serum folate (a), vitamin $B_{12}(b)$, and plasma pyridoxal phosphate (c), subdivided by tenths of their distribution, for young people aged $4-10$ years $(O)$ and $10-$ 18 years $(\bullet)$ and free-living elderly adults over 65 years of age $(\mathbf{\Lambda})$. In each part of the figure, the relationship between tHcy and the corresponding status index of one of the three key determinant B-vitamins: folate, vitamin $B_{12}$ or vitamin $B_{6}$ (pyridoxal phosphate), is depicted. The B-vitamin status values from all respondents in each age group who had both a B-vitamin and a tHcy measurement were arranged in ascending order of the B-vitamin values, and assigned a number from 1 to 10 according to the tenths of this distribution. The geometric mean value of the corresponding tHcy values was calculated for each tenth of the B-vitamin distribution and the ten resultant pairs of values were then plotted for each age group. There were approximately thirty-four values for each datapoint for the 4-10-year age group; fifty-seven values for each datapoint for the 11-18-year age group and seventy-five values for each data-point for the 65 years and over age group. For details of respondents and procedures, see p. 72 . 
Table 4. Relationships between respondent's reported current smoking status or their mother's smoking status, and their plasma homocysteine concentrations ${ }^{*} \dagger$

(Geometric mean values)

\begin{tabular}{|c|c|c|c|c|c|c|}
\hline \multirow{3}{*}{$\begin{array}{l}\text { Age group } \\
\text { (years) }\end{array}$} & \multicolumn{4}{|c|}{ Homocysteine $(\mu \mathrm{mol} / \mathrm{l})$} & \multirow[b]{3}{*}{$F$ ratio } & \multirow[b]{3}{*}{$P$} \\
\hline & \multicolumn{2}{|c|}{ Smokers } & \multicolumn{2}{|c|}{ Non-smokers } & & \\
\hline & Mean & $n$ & Mean & $n$ & & \\
\hline \multicolumn{7}{|c|}{ Respondents' own reported smoking status } \\
\hline $7-10$ & $5 \cdot 85$ & 2 & 5.52 & 202 & 0.08 & 0.8 \\
\hline $11-14$ & 6.48 & 16 & $6 \cdot 25$ & 247 & 0.20 & 0.7 \\
\hline $15-18$ & 8.53 & 78 & $7 \cdot 90$ & 171 & $2 \cdot 38$ & 0.12 \\
\hline All & $7 \cdot 11$ & 96 & 6.54 & 620 & 4.76 & 0.03 \\
\hline \multicolumn{7}{|c|}{ Maternal smoking status } \\
\hline $4-6$ & 4.58 & 32 & 4.66 & 70 & 0.11 & 0.74 \\
\hline $7-10$ & 5.95 & 69 & 5.59 & 144 & 7.9 & 0.006 \\
\hline $11-14$ & 6.51 & 81 & $6 \cdot 16$ & 181 & 1.6 & 0.21 \\
\hline $15-18$ & 8.34 & 80 & 7.92 & 158 & 1.0 & 0.31 \\
\hline All & 6.56 & 262 & $6 \cdot 17$ & 555 & $6 \cdot 7$ & 0.01 \\
\hline
\end{tabular}

${ }^{*}$ For details of respondents and procedures, see p. 72.

†Plasma homocysteine was $\log _{\mathrm{e}}$-transformed for the analysis and then backtransformed for reporting. Smoking habit was self-reported as 'yes' or 'no', without details of number of cigarettes/d and without biochemical confirmation. All models were adjusted for age and season. The significant relationship with maternal smoking status in the 7-11 year age group remained significant even after excluding those $(n 2)$ respondents who were themselves smokers. It also remained significant after further adjustment for variations in household income, receipt of benefits, gender and geographical region. Paternal smoking was not significantly correlated with total homocysteine, and neither maternal nor own reported smoking habit were correlated with cysteine and cysteinyl-glycine. The difference in total homocysteine between non-smokers whose mother was a smoker, and those whose mother was not, was also significant by the Scheffé test at $P=0.034$.

season, none of these indices exhibited any significant relationships with tHcy, in young people aged 4-18 years.

\section{Discussion}

Previously published studies in the literature of tHcy in clinically-normal children are broadly compatible with those of the present study although they vary according to the populations studied, to whether or not the subjects were divided by sex, and to whether the results were reported as arithmetic means, geometric means or medians. Several studies (de Laet et al. 1999; Jacques et al. 1999; Osganian et al. 1999) reported sex differences, with higher values in boys, especially in the older, post-pubertal age groups. Studies of children aged between 5 and 11 years have found median or geometric mean values of $5.8 \mu \mathrm{mol} / \mathrm{l}$ (Vilaseca et al. 1997), $5.5 \mu \mathrm{mol} / \mathrm{l}$ (Greenlund et al. 1999) and $6 \cdot 2 \mu \mathrm{mol} / \mathrm{l}$ (de Laet et al. 1999). For those aged $11-15$ years the medians or geometric means were $5.7 \mu \mathrm{mol} / \mathrm{l}$ (Vilaseca et al. 1997), $6 \cdot 5 \mu \mathrm{mol} / \mathrm{l}$ (Jacques et al. 1999), $7 \cdot 1 \mu \mathrm{mol} / \mathrm{l}$ (de Laet et al. 1999) and $5.0 \mu \mathrm{mol} / \mathrm{l}$ (Osganian et al. 1999). Tonstad et al. (1997) found $5 \cdot 1 \mu \mathrm{mol} / 1$ in 8-12-year-old children. For adolescents aged 15-19 years, medians or geometric means have been $8.1 \mu \mathrm{mol} / \mathrm{l}$ (Vilaseca et al. 1997), $7 \cdot 6 \mu \mathrm{mol} / \mathrm{l}$ (Jacques et al. 1999), $6 \cdot 3 \mu \mathrm{mol} / \mathrm{l}$ (Greenlund et al. 1999) and $9.0 \mu \mathrm{mol} / \mathrm{l}$ (de Laet et al. 1999). Other studies of children of unspecified ages, or with less than thirty per group, or with arithmetic means only, included Reddy (1997), Balasa et al. (1999), Koch et al. (1999) and
Table 5. Geographical distribution of homocysteine in young people aged $4-18$ years ${ }^{\star}$

(Mean values)

\begin{tabular}{|c|c|c|}
\hline Geographical subdivision & $\begin{array}{l}\text { Homocysteine } \\
\text { concentration } \\
(\mu \mathrm{mol} / \mathrm{l}) \dagger\end{array}$ & $n$ \\
\hline \multicolumn{3}{|l|}{ North-south } \\
\hline Scotland and Northern England & 6.95 & 238 \\
\hline $\begin{array}{l}\text { Central, South West, Wales, } \\
\text { London, South East }\end{array}$ & $6 \cdot 58$ & 486 \\
\hline$F$ ratio & \multirow{2}{*}{\multicolumn{2}{|c|}{$\begin{array}{c}4.6 \\
0.03\end{array}$}} \\
\hline$P$ & & \\
\hline \multicolumn{3}{|l|}{ Four main regions } \\
\hline Scotland & $7 \cdot 29$ & 57 \\
\hline Northern England & $6 \cdot 90$ & 181 \\
\hline Central, South West, Wales & $6 \cdot 67$ & 249 \\
\hline London and South East & $6 \cdot 55$ & 237 \\
\hline F ratio & \multicolumn{2}{|l|}{$2 \cdot 1$} \\
\hline$P$ & \multicolumn{2}{|l|}{$0 \cdot 10$} \\
\hline \multicolumn{3}{|l|}{ Eleven regions } \\
\hline Scotland & $7 \cdot 30$ & 57 \\
\hline Northern England & $6 \cdot 57$ & 23 \\
\hline North West & $6 \cdot 44$ & 74 \\
\hline Yorkshire + Humberside & $7 \cdot 46$ & 84 \\
\hline East Midlands & 5.89 & 55 \\
\hline West Midlands & 7.03 & 51 \\
\hline East Anglia & $6 \cdot 64$ & 45 \\
\hline London & $6 \cdot 40$ & 74 \\
\hline South East & 6.63 & 163 \\
\hline South West & $7 \cdot 15$ & 61 \\
\hline Wales & 6.75 & 37 \\
\hline$F$ ratio & \multirow{2}{*}{\multicolumn{2}{|c|}{$\begin{array}{c}2.9 \\
0.002\end{array}$}} \\
\hline$P$ & & \\
\hline
\end{tabular}

${ }^{*}$ For details of respondents and procedures, see p. 72.

†Plasma homocysteine was $\log _{\mathrm{e}}$-transformed for the analysis and then backtransformed. The models were all adjusted for age, season, household income, maternal highest qualification level, ethnic group, reported own and maternal smoking habits. Missing values in some of these categories were responsible for the reduced numbers of respondents represented, compared with previous tables. If adjusted for age and season only, the significance of the difference between subdivisions in the first two models was non-significant ( $P=0.12$ and 0.4 respectively), but that in the elevenregion model remained significant $(P=0.01)$.

Raslova et al. (2000). All of these studies, which have included the USA and several west and east European countries, are consistent with the values found in the present study of British children. Several of these, and other, studies (Tonstad et al. 1996, 1997; de Laet et al. 1999; Osganian et al. 1999; Selhub, 1999; Delvin et al. 2000) have recorded inverse relationships between homocysteine and B-vitamin status indices in children. The study by Osganian et al. (1999) recorded a weak direct relationship between tHcy and systolic blood pressure and BMI. There have not been any previously-published studies on cysteine or cysteinylglycine in children, to the authors' knowledge.

Variation of plasma tHcy with season (Table 2) has received little attention in previous studies. In the present study of young people, as in the survey of people aged 65 years and over, significantly lower tHcy levels were observed during the winter months than at other times of the year. The other two thiol species, which were measured in the same HPLC run in the same samples, exhibited dissimilar seasonal cycles. The seasonal variation in tHcy was not matched by a corresponding seasonal cycle in B-vitamin intakes, and was only partly explained by a 
seasonal cycle in B-vitamin status indices (not shown). In older people, vascular risk factors such as high blood pressure, high fibrinogen and high cholesterol levels, and also the highest prevalence of symptomatic vascular disease, generally occur in the winter months (Woodhouse et al. 1993a,b, 1994). The participants in the 4-18-year survey, in common with older people in other studies (Woodhouse et al. 1993a,b, 1994 Khaw \& Woodhouse, 1995), had significantly higher median cholesterol concentrations $(4.2$ v. $4.0 \mathrm{mmol} / \mathrm{l})$, lower median vitamin $\mathrm{C}$ concentrations $(57$ v. $62 \mu \mathrm{mol} / \mathrm{l})$, and higher median diastolic blood pressures $(56.4$ v. $54.2 \mathrm{mmHg}$ ) in the winter than in the summer.

The relationships between tHcy and B-vitamin status (Table 3; Fig. 1), which were demonstrated in the present study, concur with previous observations in adults (Brattstrom et al. 1988; Verhoef et al. 1996; Bates et al. 1997; Homocysteine-Lowering-Triallists'-Collaboration, 1998; Omenn et al. 1998; Pietrzik \& Bronstrup, 1998; Mansoor et al. 1999). The observation in the present study that plasma pyridoxic acid was a stronger covariate with tHcy than plasma pyridoxal phosphate was unexpected, since the former is an excretory degradation product whereas the latter is one of the active coenzyme forms of vitamin $B_{6}$ and is usually deemed to be the better index of status. However, extra-cellular (e.g. plasma) pools of this vitamin may be less closely related to its functional status than intracellular turnover rates. The inverse relationship between tHcy and erythrocyte superoxide dismutase (Table 3 ) contrasts with the direct relationship observed in older respondents in two recent studies (Moat et al. 2000; Wilcken et al. 2000), suggesting that there may be differences between different populations, and possibly between age groups, in this respect. The direct relationship with fasting triacylglycerol (Table 3) may have arisen because both indices decline progressively during the postprandial period, so that even in fasting blood samples, both of them may be influenced by the interval since, and macronutrient content of, the previous meal. Neither total nor HDL cholesterol shared this relationship. Serum or plasma triacylglycerol concentrations have been shown, in recent studies, to predict coronary disease (Hokanson \& Austin, 1996; Stampfer et al. 1996).

A relationship between plasma tHcy and smoking has been reported only infrequently (Refsum et al. 1998). In the oldest age group of young people in the present study there was a weak direct relationship between plasma tHcy and their own reported smoking habit (Table 4). The other smoking-related observation in the present study, namely a strong direct relationship between maternal smoking habit and plasma tHcy, principally seen in the 7-11-year-old children (Table 4), was unexpected. A direct effect of passive smoking seems inherently unlikely. Alternatively, maternal smoking habit may covary with other lifestyle risk factors, which may impinge particularly strongly on younger children, who spend a high proportion of their time at home. This relationship with maternal smoking was not, however, attenuated by adjustment for a number of indices of socio-economic status. Clearly the mechanism requires further investigation.

Geographical gradients in tHcy were less strong in the present study (Table 5) than in the survey of older people (Bates et al. 1997), but they were in the same direction, namely higher concentrations in the north than the south. Moreover, the B-vitamin status indices which were correlated inversely with tHcy were consistently higher in the south than the north. Further information about the geographical variation of nutritional status indices and the corresponding nutrient intakes can be found in the survey reports (Finch et al. 1998; Gregory et al. 2000).

Many recent studies have indicated that plasma tHcy is a potent risk indicator for vascular disease (Boushey, 1995; Refsum et al. 1998; Welch \& Loscalzo 1998; Nygard et al. 1999; Selhub, 1999) and is largely independent of other major risk indicators such as blood cholesterol, blood pressure and platelet function. Explanatory hypotheses have been formulated, usually based on endothelial damage, and it has been argued that those interventions which can lower tHcy levels may also reduce the risk of vascular disease in later life. This remains an unproven, though attractive, hypothesis, and it is now being tested by several ongoing intervention studies. Recent studies (Mansoor et al. 1995; El-Khairy et al. 1999, 2001) have indicated an important, possibly separate, role for plasma cysteine. By exploring the range of influences that impinge on both plasma tHcy and cysteine early in life, it may be possible to identify those factors which (a) contribute to later risk, and (b) are modifiable by dietary or lifestyle modification.

Because the population sample used for the present study was a representative sample of young people drawn by random selection from all parts of mainland Britain, it provides reference values for future studies, provided that the assay methodologies are comparable. The existence of widely available external quality assurance schemes (for example, see Moller et al. 1999) to which the present study was linked, will help to ensure inter-laboratory and interstudy comparability. Our comparison between the three plasma thiol species in young and older people illustrates the considerable magnitude and statistical significance of the change in plasma tHcy that is attributable to ageing. It is likely that the progressive increase in plasma tHcy with age has a variety of determinants, not all of which have yet been identified.

In conclusion, the present study has demonstrated a progressive increase in plasma tHcy with age, and strong inverse relationships with blood indices of folate, vitamin $\mathrm{B}_{12}$ and vitamin $\mathrm{B}_{6}$ status, but it has also revealed some unexpected relationships, including a seasonal variation, with lowest values in the winter, and a direct relationship with maternal smoking habit in 7-10-year-old children. It has provided normative values for plasma tHcy, cysteine and cysteinyl-glycine for young people living in mainland Britain. The relevance of these indices for later disease risk, and their response to intervention, remains an important subject for future research.

\section{Acknowledgements}

The study was part of the NDNS of young people aged 4-18 years, which was conducted by the Social Survey Division of the Office for National Statistics in conjunction with Medical Research Council Human Nutrition Research 
(formerly part of the Medical Research Council Dunn Nutrition Unit). The authors are indebted to Mrs Ieda Aziz Slewa for technical assistance with the homocysteine, cysteine and cysteinyl-glycine assays.

\section{References}

Alfthan G, Pekkanen J, Jauhianen M, Pitkaniemi J, Karvonen M, Tuomilehto J, Salonen JT \& Ehnholm C (1994) Relation of serum homocysteine and lipoprotein(a) concentrations to atherosclerotic disease in a prospective Finnish population based study. Atherosclerosis 106, 9-19.

Arnesen E, Refsum H, Bonna K, Ueland P \& Forde O (1995) Serum total homocysteine and coronary heart disease. International Journal of Epidemiology 24, 704-709.

Balasa V, Gruppo R, Gartside P \& Kalinyak K (1999) Correlation of the C677T MTHFR genotype with homocysteine levels in children with sickle cell disease. Journal of Pediatric Hematology and Oncology 21, 397-400.

Bates CJ, Mansoor MA, van der Pols J, Prentice A, Cole TJ \& Finch S (1997) Plasma total homocysteine in a representative sample of 972 British men and women aged 65 and over. European Journal of Clinical Nutrition 51, 1-7.

Bates CJ, Pentieva KD, Matthews N \& Macdonald A (1999a) A simple, sensitive and reproducible assay for pyridoxal phosphate in human plasma. Clinica Chimica Acta 280, 101-111.

Bates CJ, Pentieva KD \& Prentice A (1999b) An appraisal of vitamin B6 status indices and associated confounders, in young people aged 4-18 years and in people aged 65 years and over, in two national British surveys. Public Health Nutrition 2, $529-535$.

Boushey CJ (1995) A quantitative assessment of plasma homocysteine as a risk factor for vascular disease Probable benefits of increasing folic acid intakes. Journal of the American Medical Association 274, 1049-1057.

Brattstrom L, Israelsson B, Jeppson J-O \& Hultberg B (1988) Folic acid - an innocuous means to reduce plasma homocysteine. Scandinavian Journal of Clinical and Laboratory Investigation 48, 215-221.

Danesh J \& Lewington S (1998) Plasma homocysteine and coronary heart disease: systematic review of published epidemiological studies. Journal of Cardiovascular Risk 5, 229-232.

De Laet C, Wautrecht J-C, Brasseur D, Dramaix M, Boeynaems J-M, Decuyper J \& Kahn A (1999) Plasma homocysteine concentrations in a Belgian school-age population. American Journal of Clinical Nutrition 69, 968-972.

Delvin EE, Rozen R, Merouani A, Genest J Jr \& Lambert M (2000) Influence of methylenetetrahydrofolate reductase genotype, age, vitamin B-12 and folate status on plasma homocysteine in children. American Journal of Clinical Nutrition $\mathbf{7 2}$, 1469-1473.

El-Khairy L, Ueland P, Nygard O, Refsum H \& Vollset S (1999) Lifestyle and cardiovascular disease risk factors as determinants of total cysteine in plasma: the Hordaland Homocysteine Study. American Journal of Clinical Nutrition 70, 1016-1024.

El-Khairy L, Ueland P, Refsum H, Graham IM \& Vollset S (2001) Plasma total cysteine as a risk factor for vascular disease The European Concerted Action Project. Circulation 103, 2544.

Enoiu M, Aberkane H, Salazar JF, Leroy P, Groffen J, Siest G \& Wellman M (2000) Evidence for the pro-oxidant effect of gamma-glutamyl transpeptidase-related enzyme. Free Radicals in Biology and Medicine 29, 825-833.

Finch S, Doyle W, Lowe C, Bates CJ, Prentice A, Smithers G \& Clarke P (1998) Report of the Diet and Nutrition Survey vol. 1,
National Diet and Nutrition Survey: People Aged 65 Years or Over, London: HM Stationery Office.

Fiore M, Mitchell J, Doan T, Nelson R et al. (1988) The Abbott $\mathrm{IMx}^{\mathrm{TM}}$ Automated Benchtop Immunochemistry Analyzer System. Clinical Chemistry 34, 1726-1732.

Fiskerstrand T, Refsum H, Kvalheim G \& Ueland P (1993) Homocysteine and other thiols in plasma and urine: automated determination and sample stability. Clinical Chemistry 39, $263-271$.

Greenlund K, Srinivasan S, Xu J-H, Dalferes E, Myers L, Pickoff A \& Berenson G (1999) Plasma homocysteine distribution and its association with parental history of coronary artery disease in black and white children. Circulation 99, 2144-2149.

Gregory J, Lowe S, Bates C, Prentice A, Jackson L, Smithers G, Wenlock R \& Farron M (2000) Report of the Diet and Nutrition Survey vol. 1, National Diet and Nutrition Survey: Young People Aged 4 to 18 Years, London: The Stationery Office.

Hokanson JE \& Austin MA (1996) Plasma triglyceride level is a risk factor for cardiovascular disease independent of highdensity lipoprotein cholesterol: a meta-analysis of population based prospective studies. Journal of Cardiovascular Risk 3, 213-219.

Homocysteine-Lowering-Triallists'-Collaboration (1998) Lowering blood homocysteine with folic acid based supplements: meta-analysis of randomised trials. British Medical Journal 316, 894-898.

Israelsson B, Brattstrom L \& Refsum H (1993) Homocysteine in frozen plasma samples A short cut to establish hyperhomocysteinaemia as a risk factor for arteriosclerosis? Scandinavian Journal of Clinical and Laboratory Investigation 53, 465-469.

Jacques P, Rosenberg I, Rogers G, Selhub J, Bowman B, Gunter E, Wright J \& Johnson C (1999) Serum total homocysteine concentrations in adolescent and adult Americans: results from the third National Health and Nutrition Examination Survey. American Journal of Clinical Nutrition 69, 482-489.

Khaw K \& Woodhouse P (1995) Interrelation of vitamin C, infection, haemostatic factors, and cardiovascular disease. British Medical Journal 310, 1559-1563.

Koch H, Nabel P, Junker R, Auberger K, Schobess R, Homberger A, Linnebank M \& Nowak-Gottl U (1999) The 677T genotype of the common MTHFR thermolabile variant and fasting homocysteine in childhood venous thrombosis. European Journal of Pediatrics 158, Suppl. 3, S113-S116.

Kuemmerle S, Boltinghouse G, Delby S, Lane T \& Simondsen R (1992) Automated assay of vitamin B-12 by the Abbott IMx ${ }^{\mathrm{TM}}$ analyzer. Clinical Chemistry 38, 2073-2077.

Malinow MR, Duell PB, Hess DL, Anderson PH, Kruger WD, Phillipson BE, Gluckman RA, Block PC \& Upson BM (1998) Reduction of plasma homcyst(e)ine levels by breakfast cereal fortified with folic acid in patients with coronary heart disease. New England Journal of Medicine 15, 1009-1015.

Mansoor M, Svardal A \& Ueland P (1992) Determination of the in vivo redox status of cysteine, cysteinylglycine, homocysteine and glutathione in human plasma. Analytical Biochemistry 200, 218-229.

Mansoor MA, Bergmark C, Haswell SJ, Savage IF, Evans PH, Berge RK, Svardal AM \& Kristenson O (2000) Correlation between plasma total homocysteine and copper in patients with peripheral vascular disease. Clinical Chemistry 46, 385-391.

Mansoor MA, Bergmark C, Svardal AM, Lonning PE \& Ueland PM (1995) Redox status and protein binding of plasma homocysteine and other aminothiols in patients with earlyonset peripheral vascular disease. Arteriosclerosis, Thrombosis and Vascular Biology 15, 232-240.

Mansoor MA, Kristensen O, Hervig T, Bates CJ, Pentieva K, Vefring $\mathrm{H}$, Osland A, Berge $\mathrm{T}$, Drablos PA, Hetland $\mathrm{O}$ \& 
Rolfsen S (1999) Plasma total homocysteine response to oral doses of folic acid and pyridoxine hydrochloride (vitamin $\mathrm{B}_{6}$ ) in healthy individuals. Oral doses of vitamin $\mathrm{B}_{6}$ reduce concentrations of serum folate. Scandinavian Journal of Clinical and Laboratory Investigation 59, 139-146.

Moat S, Bonham J, Cragg R \& Powers H (2000) Elevated plasma homocysteine elicits an increase in antioxidant enzyme activity. Free Radical Research 32, 171-179.

Moller J, Rasmussen K \& Christensen L (1999) External quality assessment of methylmalonic acid and total homocysteine. Clinical Chemistry 45, 1536-1542.

Nygard O, Vollset S, Refsum H, Brattstrom L \& Ueland P (1999) Total homocysteine and cardiovascular disease. Journal of Internal Medicine 246, 425-454.

Omenn GS, Beresford SAA \& Motulsky AG (1998) Preventing coronary heart disease: B-vitamins and homocysteine. Circulation 97, 421-424.

Osganian S, Stampfer M, Spiegelman D, Rimm E, Cutler J, Feldman H, Montgomery D, Webber L, Lytle L, Bausserman L \& Nader P (1999) Distribution of and factors associated with serum homocysteine levels in children. Child and adolescent trial for cardiovascular health. Journal of the American Medical Association 281, 1189-1196.

Pietrzik K \& Bronstrup A (1998) Vitamins B12 B6 and folate as determinants of homocysteine concentration in the healthy population. European Journal of Pediatrics 157, Suppl. 2, S135-S138.

Raslova K, Bederova A, Gasparovic J, Blazicek P \& Smolkova B (2000) Effect of diet and $677 \mathrm{C} \rightarrow \mathrm{T}$ 5,10-methylenetetrahydrofolate reductase genotypes on plasma homocysteine concentrations in Slovak adolescent population. Physiological Research 49, 651-658.

Reddy M (1997) Reference ranges for total homocysteine in children. Clinica Chimica Acta 262, 153-155.

Refsum H, Ueland PM, Nygaard O \& Vollset SE (1998) Homocysteine and cardiovascular disease. Annual Review of Medicine 49, 31-62.

Robinson K, Arheart K, Refsum H, Brattström L, Boers G, Ueland P, Rubba P, Palma-Reis R, Meleady R, Daly L, Witteman J \& Graham I (1998) Low circulating folate and vitamin B6 concentrations. Risk factors for stroke, peripheral vascular disease and coronary artery disease. Circulation 97, 437-443.

Rosenberg IH (1996) Homocysteine, vitamins and arterial occlusive disease: an overview. Journal of Nutrition 126, Suppl., 1235S-1237S.

Selhub J (1999) Homocysteine metabolism. Annual Review of Nutrition 19, 217-246.

Stampfer M, Krauss R \& Ma J (1996) A prospective study of triglyceride level, low-density lipoprotein particle diameter, and risk of myocardial infarction. Journal of the American Medical Association 276, 882-888.

Tonstad S, Refsum H, Sivertsen M, Christophersen B, Ose L \& Ueland P (1996) Relation of total homocysteine and lipid levels in children to premature cardiovascular death in male relatives. Pediatric Research 40, 47-52.

Tonstad S, Refsum H \& Ueland P (1997) Association between plasma total homocysteine and parental history of cardiovascular disease in children with familial hypercholesterolemia. Circulation 96, 1803-1808.

Ueland P, Refsum H \& Brattstrom L (1992) Plasma homocysteine and cardiovascular disease. In Atherosclerotic Cardiovascular Disease, Hemostasis and Endothelial Function, pp. 183-236 [RBJ Francis, editor]. New York: Marcel Dekker Inc.

Ueland PM, Mansoor MA, Guttormsen AB, Muller F, Aukrust P, Refsum H \& Svardal AM (1996) Reduced, oxidized and proteinbound forms of homocysteine and other aminothiols in plasma comprise the redox thiol status - a possible element of the extracellular antioxidant defense system. Journal of Nutrition 126, 1281S-1284S.

Verhoef P, Stampfer MJ, Buring JE, Gaziano JM, Allen RH, Stabler SP, Reynolds RD, Kok FJ, Hennekens CH \& Willett WC (1996) Homocysteine metabolism and risk of myocardial infarction: relation with vitamins B6, B12, and folate. American Journal of Epidemiology 143, 845-859.

Vilaseca M, Moyano D, Ferrer I \& Artuch R (1997) Total homocysteine in pediatric patients. Clinical Chemistry 43, 690-692.

Welch GN \& Loscalzo J (1998) Homocysteine and atherosclerosis. New England Journal of Medicine 338, 1042-1050.

Wilcken D, Wang X, Adachi T, Hara H, Duarte N, Green K \& Wilcken B (2000) Relationship between homocysteine and superoxide dismutase in homocystinuria. Possible relevance to cardiovascular disease. Arteriosclerosis, Thrombosis and Vascular Biology 20, 1199-1202.

Wilson D, Herrmann R, Hsu S, Biegalski T, Sohn L, Forsythe C, Novotny M, Beggs M \& Mandarino G (1995) Ion capture assay for folate with the Abbott $\mathrm{IMx}^{\mathrm{TM}}$ analyzer. Clinical Chemistry 41, 1780-1781.

Woodhouse P, Khaw K \& Plummer M (1993a) Seasonal variation of blood pressure and its relationship to ambient temperature in an elderly population. Journal of Hypertension 11, 1267-1274.

Woodhouse P, Khaw K \& Plummer M (1993b) Seasonal variation of serum lipids in an elderly population. Age and Ageing 22, 273-278.

Woodhouse PR, Khaw KT, Plummer M, Foley A \& Meade TW (1994) Seasonal variations of plasma fibrinogen and factor VII activity in the elderly: winter infections and death from cardioivascular disease. Lancet 343, 435-439. 